\title{
Scientific Collaboration, Citation and Topic Analysis of International Conference on Agile Software Development Papers
}

M uhammad Ovais Ahmad (1, 2) and Päivi Raulamo-Jurvanen (3)

1. Department of M athematics and Computer Science, Karlstad University, Sweden.

2. Faculty of Electronics, Telecommunications and Informatics, Gdansk University of Technology, Poland.

3. M 3S Research Unit, University of Oulu, Finland

ovais.ahmad@kau.se

paivi.raulamo-jurvanen@oulu.fi

\begin{abstract}
The International Conference on Agile Software Development (XP) was established almost sixteen years ago. Based on data from Scopus database, a total of 789 papers have been published in between years of 2002 and 2018. We employed bibliometrics analysis and topic modeling with R/RStudio to analyze these published papers from various dimensions, including the most active authors, collaboration of authorship, most cited papers, used keywords and trends of probable topics from the titles and abstracts of those papers. The results show that the first five years of XP conference cover nearly $40 \%$ of the papers published until now and almost $62 \%$ of the XP papers have been cited at least once. Mining of XP conference paper titles and abstracts result in these hot research topics: "Coordination", "Technical Debt", "Teamwork", "Startups" and "Agile Practices", thus strongly focusing on practical issues and problems faced by the practitioners in the industry. The results high-light the most influential researchers and institutions, and the collaboration between the authors in the conference papers. The approach applied in this study can be extended to other software engineering venues and can be applied to large-scale studies.
\end{abstract}

Keywords: Bibliometrics, Software Engineering, Publication Mining, Citation Analysis, International Conference on Agile Software Development.

\section{Introduction}

"Publish or perish" is a commonly used idiom in the academic community. The phrase frames the pressure for rapid publishing to sustain or move forward in one's academic career. Research articles and other papers are being published in various venues such as conferences and journals. Such published work is taken seriously into consideration in almost all types of research funding for researchers in the academia and other research institutes. In addition, in academia, it is common to quantify the impact of published papers by analyzing the number of citations for those. Citation is one way to judge influential work and build new studies on existing research results. Citations may be helpful in observing the most popular and influential work in the field [6, 23, 21]. However, as pointed out by Wohlin [22], outcome and trustworthiness of the findings can be very much dependent on the actual tool(s) or source(s) used for collecting the data for the citation analysis.

Garfield put systematic effort to track the citations in scientific literature and published the Science Citation Index [7]. Further, bibliometrics methods use statistical analysis of publications to shed light on quantitative analysis [19]. Bibliometrics based identification of active authors and institutions has many benefits, e.g., in 
helping students and researchers to identify active and relevant institutes for their areas of interest, and in enabling employers to assess and recruit the most qualified potential researchers [21, 1]. Citation analysis and bibliometrics have been used to identify influential work and researchers e.g., in Medicine, Physics, Software Engineering (SE), Social Sciences and other fields of science $[10,23,21,12,14,18,13,3,15,1]$.

In the last decade, a number of citation and bibliometrics studies have been published in the field of SE. For instance, between 1999 and 2002, Wohlin published a series of papers with a goal of identifying the most cited papers, and invited authors of the most cited papers to contribute to a special section of the Information and Software Technology journal [22-24]. Kitchenham [16] con-ducted study with a focus on software metrics and identified the most cited papers published between 2000 and 2005 . The study further classified the main topics, goals and empirical content of those papers [16]. Further, a number of bibliometric studies have been conducted identifying the top SE scholars and institutions in various timelines. For example, Garousi and Varma [11] present a bibliometric assessment of Canadian SE scholars and institutions. Farhoodi et al. [5] reported the most active authors in the area of development of scientific software to be located mainly in the US, followed by the Canadian and British researchers. Recently, a study by Garousi and Fernandes [8] identified and classified the top-100 highly-cited SE papers in terms of two metrics: total number of citations and average annual number of citations. In the context of agile software development, a study by Chuang, Luor and Luo [3] reported top publications, institutions, and scholars in the agile software development field from 2001 to2012 based on the publication of such works in Science Citation Index journals. However, there are only a few citation

or bibliometrics SE studies conducted in small-scale, i.e., focusing only on a selected venue or a subset of venues $[21,8]$. A small-scale study on a selected venue may reveal interesting insights not only into the emerging research topics within but also into the authorship of the papers, i.e., collaboration among the authors regarding the research topics.

One of the key outlets for Agile research, "Agile Software Development Conference (XP)", has not been evaluated under the lens of citation analysis alone or as a sub-field of its own (processes). XP Conference ("International Conference on Extreme Programming (XP)", formerly known as "Conference on Agile Software Development (AGILE)") was included in a bibliometrics study of Karanatsiou et al. [15] in the general domain of SE. In that study, XP conference was the only process-oriented conference [15]. In fact, XP conference is the premier Agile software development conference combining research and practice. This paper is an extension of our previously published paper [1] entitled "Preliminary Citation and Topic Analysis of International Conference on Agile Software Development Papers (2002-2018)" published in 14th Federated Conference on Computer Science and Information Systems (FedCSIS 2019). This study provides an overview of the literature published in all XP conference proceedings $(n=789)$. This study helps readers to understand the development and evolution of the XP conference from three main aspects: (i) the citation landscape and the most cited papers, (ii) the most active authors, institutions and countries, in terms of number of publications, and (iii) the identification of emerging research topics in XP conference publications and use of indexed keywords. Further-more, this paper extends our prior study [1] by comparing the results to other researches, in more detail, and by analyzing the collaboration of the authors within the XP conference papers.

This paper is organized as follows: First, we discuss the research method and the data extraction technique. Second, we present the results of the analysis including findings on authorship trends, active individuals and institutes, highly cited papers and authors, trends in the covered topics, most common keywords in the papers and collaboration of the authors within the conference. Third, we discuss the threats to validity of the study. Finally, we summarize the findings and provide recommendations for future research. 


\section{Data Extraction and Research Method}

The data for the analysis was fetched from Scopus (https://www.elsevier.com/solutions/scopus) on September 2nd, 2018. Scopus is claimed to be the largest abstract and citation database of peer-reviewed literature and designed to serve the needs of academic, business and government. Thus, anyone having access to Scopus data has the possibility to perform similar queries without having to have technical skills for e.g., some Application Programming Interface (API). Scopus also provides citation data and allows saving the search results to a csv-file for further analysis. We used two search queries to obtain all XP conference data from the Scopus database, see Table 1.

Table 1

\begin{tabular}{|lll|}
\hline No. & Query String (as to be given in Scopus) and its explanation & Papers \\
1 & $\begin{array}{l}\text { CONF("XP") AND DOCTYPE("cp") } \\
\text { Select XP conference and conference papers only }\end{array}$ & 758 \\
\hline & $\begin{array}{l}\text { SRCTITLE("lecture notes in business information processing" AND } \\
\text { VOLUM E(77) AND DOCTYPE("cp") }\end{array}$ & \\
2 & $\begin{array}{l}\text { Select "Lecture Notes in Business Information Processing" and only } \\
\text { volume 77 (which includes conference papers for XP 2011) }\end{array}$ & 31 \\
\hline & & 789 \\
\hline
\end{tabular}

The first query was used with an assumption that it would provide us with all the published XP conference papers. However, the search resulted in 758 papers and it became evident that the data set did not include the papers from the year 2011. One reason was the year 2011 does not include the information about the XP conference in the Scopus database. Thus, we formulated another search query to obtain the missing papers from the Scopus database. The second search query (for 2011 only) retrieved 31 papers. The two search queries together retrieved 789 papers $(758+31)$, covering the years of 2002-2018 (published by September 2nd, 2018). The Fig. 1, shows the distribution of papers published by September 2nd, 2018.

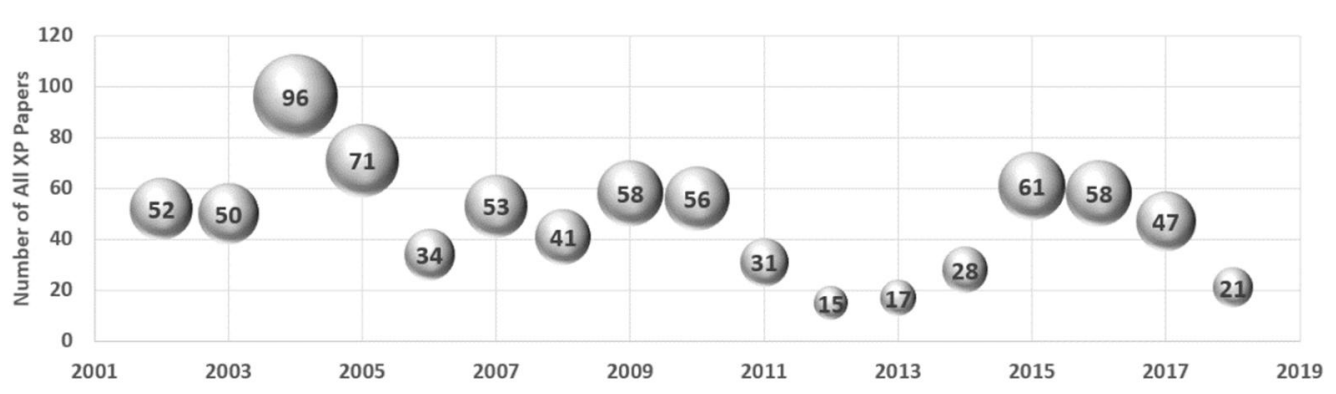

Figure 1. All publications for the XP conference in Scopus (2002-2018)

The data acquired from Scopus (included e.g., names of the authors, title, publication year, source title, number of citations, link and abstract) were stored in a csv-file. The Scopus database also provided features to extract data for the analysis of the affiliations and countries related to the authors (analysis of the search results in Scopus) as well as the top 20 cited papers (overview of the citations in Scopus). First, the data allowed us to study the affiliations, countries and authors contributing to the research the most. Second, regarding the authors, we could count the number of papers for each author as well as the degree of collaboration among those authors. Third, the number of citations for all papers and data for the top 20 most cited papers allowed us to analyze the overall citation landscape, the highest cited papers and annual 
citations for the top cited papers. Additionally, we used topic modeling for the trend analysis (of the titles and abstracts in the data), see Section 3.4.

We used MS Excel and R/RStudio for analyzing statistics and trends from the data. Many times, a table of data may serve the purpose of presenting the results, but sometimes a figure may be more descriptive or provide perspective on an issue. Thus, in addition, we used Cytoscape (https://cytoscape.org/), an open source software platform, for visualizing the relationships of keywords and networks of authors in the data.

\section{$3 \quad$ Results}

The first "XP Universe" took place in Raleigh, North Carolina, on July 23-25, 2001. The conference hosted a number of lectures, tutorials, panel discussions, posters, workshops, and other less traditional discussions. A year later, the $2^{\text {nd }}$ "XP Universe" and 1st "Agile Universe" were brought together to attract software experts, educators, and developers 7, in general. In 2003 and 2004, the two conferences, "Extreme Programming and Agile M ethods - XP/Agile Universe" and "Extreme Programming and Agile Processes in Software Engineering" were organized separately but reported together in a Springer database. In 2005, the conferences were merged and formed a single venue: "Extreme Programming and Agile Processes in Software Engineering". Since 2007, the conference has been called as "Agile Processes in Software Engineering and Extreme Programming".

The Scopus database search yielded 789 papers in the proceedings of XP conference published between 2002 and 2018. In the bubble chart, see Fig. 2, the year is displayed along the horizontal axis, the number of all conference papers is shown along the vertical axis and the total number of "full papers" indexed in the Scopus database is represented by the size of the bubble. The values in the bubbles, in Fig. 2, represent the number of full papers vs. the number of all papers (included in this research per year). The high number of papers for 2004 ( $n=96$ including 23 "full papers" that year) is explained by the fact that the two aforementioned conferences are recorded together.

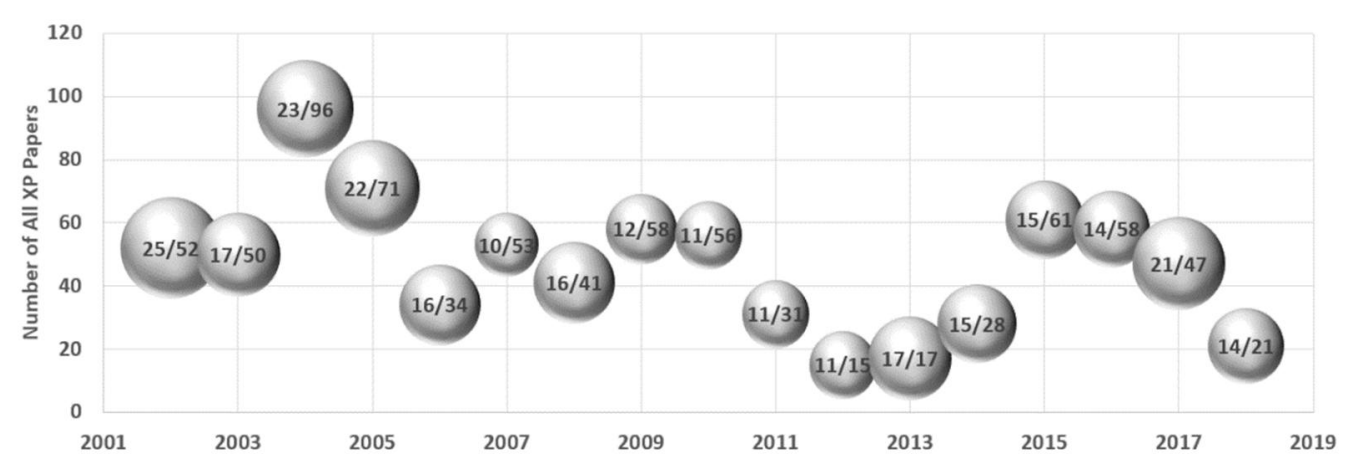

Figure 2. Publications in Scopus (2002-2018), bubble size representing the number of full papers and the values within showing the number of full vs. all papers for each year

The first five years of the XP conference cover about 38\% and the first 10 years cover nearly $70 \%$ of all those papers. In XP conference, the average number of papers per year is 46.4 with a standard deviation of 20.3, using STDEV.P. The lowest number of all papers are from year $2012(n=15)$. The low number of papers may be an indication of rigorous selection process. Alternatively, some of the volumes include only research papers and short papers, whereas, some include e.g., abstracts of the posters or the position papers of the $\mathrm{PhD}$ symposium. Such variations are quite normal in various publication forums. The first values in Fig. 2 are the values from Scopus (number of all papers) and the second values represent the number of accepted full papers retrieved from the prefaces of the relevant conference books. Two of the conference proceedings, 
XP2014 \& XP2012, did not report the number of submitted full papers. However, the acceptance rates for the conference varied between 20\% (XP2011) and 49\% (XP2003), arithmetic mean of the rates being 32\%.

The results of the number of published papers were divided into three different regions, i.e., North America, Europe and Others, to provide visibility to XP papers country-wise. The analysis shows that majority of the XP conference papers originated from Europe and North America. The countries on the top of the contribution are: United States (116), United Kingdom (110), Italy (81) and Nordic countries (Finland (66), Sweden (61) and Norway (58)), see Table 2. Based on the contribution of those countries to XP conference papers it is reasonable to assume there exists a strong culture of agile in software development.

Table 2. Top 20 Countries with most papers (2002-2018)

\begin{tabular}{|llllr|}
\hline Region & Country & Papers & Country & Papers \\
\hline North America & United States & 116 & Canada & 57 \\
\hline Europe & United Kingdom & 110 & Austria & 20 \\
\hline & Italy & 81 & Netherlands & 20 \\
\hline & Finland & 66 & Spain & 20 \\
\hline & Sweden & 61 & Denmark & 15 \\
\hline & Norway & 58 & Poland & 13 \\
\hline & Germany & 50 & Switzerland & 12 \\
\hline & Ireland & 37 & Belgium & 8 \\
\hline Others & New Zealand & 39 & Australia & 14 \\
\hline & Brazil & 25 & Israel & 13 \\
\hline
\end{tabular}

The Table 3 shows the most frequent contributing institutions in XP conference. It was noticed that authors have reported their affiliations in a variety of ways such as: SINTEF, SINTEF Digital and SINTEF Norwegian Inst. of Tech. However, the top three affiliations contributing to the papers are University of Calgary, Canada, SINTEF, Norway and Free University of Bozen-Bolzano, Italy and Università degli Studi di Cagliari, Italy. It is notable, that the number of countries and affiliations is related to the number of related authors for each paper. The study of Chuang et al. [3] did not report the total number of papers per country but reported the top publishing institutions to be from the United States, Norway and United Kingdom.

Table 3. Affiliations with minimum 15 papers

\begin{tabular}{|llrr|}
\hline Country & Affiliation & Papers & Total \\
\hline Canada & University of Calgary & 39 & 39 \\
\hline Norway & SINTEF, Norwegian Institute of Technology & 22 & 57 \\
\hline & SINTEF Digital & 16 & \\
\hline & Norges teknisk-naturvitenskapelige universitet & 19 & \\
\hline Italy & Free University of Bozen-Bolzano & 29 & 57 \\
\hline & Universita degli Studi di Cagliari & 28 & \\
\hline New Zealand & Victoria University of Wellington & 20 & 20 \\
\hline Sweden & Chalmers University of Technology & 17 & 17 \\
\hline United Kingdom & Open University & 16 & 16 \\
\hline
\end{tabular}




\subsection{Authorship Trends}

We studied the number of authors for the papers, year-wise. The results show that 1263 unique authors contributed to the 789 papers in XP conferences until 2018. The minimum number of authors for a XP paper was one whereas maximum was nine. Majority of the XP papers in 2018 (almost 35\%) have four authors. In general, about $30 \%$ of all papers have two authors, $25 \%$ have one author, and $9 \%$ of the papers have five or more authors, see Table 4. The number of authors having contributed to three or more XP papers is rather small, as most authors have contributed to just one or two papers. About $75 \%$ of the authors (944) have an authorship to just one paper and about $88 \%$ of the authors (1108) have an authorship to only one or two papers, as a single or as a co-author. Chuang et al. [3] also reported a finding of a core intellectual pool contributing to the agile research realm.

Table 4. Proportion of the number of the authors per year

\begin{tabular}{cccccccccc}
\hline \multirow{2}{*}{ Year } & & & \multicolumn{7}{c}{ Number of Authors } \\
& 1 & 2 & 3 & 4 & 5 & 6 & 7 & 8 & 9 \\
\hline 2002 & $46.2 \%$ & $30.8 \%$ & $9.6 \%$ & $1.9 \%$ & $5.8 \%$ & $1.9 \%$ & $1.9 \%$ & $0.0 \%$ & $1.9 \%$ \\
2003 & $44.0 \%$ & $30.0 \%$ & $12.0 \%$ & $6.0 \%$ & $2.0 \%$ & $4.0 \%$ & $2.0 \%$ & $0.0 \%$ & $0.0 \%$ \\
2004 & $41.7 \%$ & $32.3 \%$ & $13.5 \%$ & $7.3 \%$ & $1.0 \%$ & $3.1 \%$ & $1.0 \%$ & $0.0 \%$ & $0.0 \%$ \\
2005 & $26.8 \%$ & $36.6 \%$ & $21.1 \%$ & $9.9 \%$ & $2.8 \%$ & $0.0 \%$ & $1.4 \%$ & $1.4 \%$ & $0.0 \%$ \\
2006 & $14.7 \%$ & $32.4 \%$ & $17.6 \%$ & $26.5 \%$ & $8.8 \%$ & $0.0 \%$ & $0.0 \%$ & $0.0 \%$ & $0.0 \%$ \\
2007 & $22.6 \%$ & $37.7 \%$ & $15.1 \%$ & $17.0 \%$ & $7.5 \%$ & $0.0 \%$ & $0.0 \%$ & $0.0 \%$ & $0.0 \%$ \\
2008 & $9.8 \%$ & $39.0 \%$ & $29.3 \%$ & $9.8 \%$ & $4.9 \%$ & $0.0 \%$ & $4.9 \%$ & $0.0 \%$ & $2.4 \%$ \\
2009 & $24.1 \%$ & $34.5 \%$ & $19.0 \%$ & $13.8 \%$ & $3.4 \%$ & $1.7 \%$ & $3.4 \%$ & $0.0 \%$ & $0.0 \%$ \\
2010 & $25.0 \%$ & $19.6 \%$ & $33.9 \%$ & $17.9 \%$ & $1.8 \%$ & $1.8 \%$ & $0.0 \%$ & $0.0 \%$ & $0.0 \%$ \\
2011 & $16.1 \%$ & $19.4 \%$ & $41.9 \%$ & $19.4 \%$ & $3.2 \%$ & $0.0 \%$ & $0.0 \%$ & $0.0 \%$ & $0.0 \%$ \\
2012 & $6.7 \%$ & $33.3 \%$ & $53.3 \%$ & $0.0 \%$ & $6.7 \%$ & $0.0 \%$ & $0.0 \%$ & $0.0 \%$ & $0.0 \%$ \\
2013 & $5.9 \%$ & $23.5 \%$ & $17.6 \%$ & $47.1 \%$ & $5.9 \%$ & $0.0 \%$ & $0.0 \%$ & $0.0 \%$ & $0.0 \%$ \\
2014 & $14.3 \%$ & $21.4 \%$ & $17.9 \%$ & $25.0 \%$ & $10.7 \%$ & $10.7 \%$ & $0.0 \%$ & $0.0 \%$ & $0.0 \%$ \\
2015 & $13.1 \%$ & $27.9 \%$ & $23.0 \%$ & $21.3 \%$ & $6.6 \%$ & $3.3 \%$ & $1.6 \%$ & $3.3 \%$ & $0.0 \%$ \\
2016 & $25.9 \%$ & $27.6 \%$ & $25.9 \%$ & $8.6 \%$ & $5.2 \%$ & $6.9 \%$ & $0.0 \%$ & $0.0 \%$ & $0.0 \%$ \\
2017 & $10.6 \%$ & $21.3 \%$ & $29.8 \%$ & $23.4 \%$ & $8.5 \%$ & $4.3 \%$ & $2.1 \%$ & $0.0 \%$ & $0.0 \%$ \\
2018 & $9.5 \%$ & $23.8 \%$ & $23.8 \%$ & $33.3 \%$ & $9.5 \%$ & $0.0 \%$ & $0.0 \%$ & $0.0 \%$ & $0.0 \%$ \\
\hline Total & $24.7 \%$ & $29.8 \%$ & $21.8 \%$ & $14.6 \%$ & $4.8 \%$ & $2.4 \%$ & $1.3 \%$ & $0.4 \%$ & $0.3 \%$ \\
\hline
\end{tabular}

During the first three years (2002-2004) of the conference, most papers were published by a single author. For the years 2005-2009, most papers were published by two authors, and for the years 2010-2012 and 20132014 by three and four authors, respectively. We consider the different number of authors for the papers as an indication of increased, high (international) collaboration among the contributors. In the 1970's, the average number of authors per paper in SE was around 1.5, while after 2010, the number of authors has typically been three [8]. The average number (i.e., arithmetic mean) of authors for the papers in XP conference is 2.6 .

Asknes [2] studied a large body of Norwegian articles, nearly 50000 articles having at least one Norwegian address. He concluded that at an aggregated, general level the "highly cited papers typically involve more collaborative research than what is the normal or average" [2]. However, in our study, the correlation between the number of authors and the number of citations for a paper, considering all papers, is weak $(r=$ $0: 13 ; d f=787 ; p=0: 0002$. However, for the set of top 20 cited papers (see Table 6 ), the correlation between the number of authors and the number of citations for a paper is $0.59(r=0: 59 ; d f=18 ; p=0: 0064$. Thus, the 
correlation coefficient suggests a strong positive correlation between the number of authors and the number of citations for those top 20 cited papers.

Table 5 includes the 16 most active authors in the XP conference who have minimum number of 10 papers each. Maurer $F$. has been the most active author compared to the other top contributors of the XP conference. There are four authors that have their most cited papers published in 2010's (the publication year for the most cited paper in parenthesis), namely Abrahamsson P. (2015), Wang X. (2015), Concas G. (2012) and Bosch J. (2012); the rest of those most cited papers have been available for ten years or more. Interestingly, in a study "Institutions, scholars and contributions on agile software development (2001-2012)" by Chuang et al. [3], the list of the 18 most active authors included four of the 20 most active authors in this study, namely Abrahamsson P., Dingsøyr T., M oe, N.B. and Sharp H. However, the list of the most active authors in that study [3] included also Boehm, B., Robinson H., Williams L., Dingsøyr T., M oe, N.B. and Sharp $\mathrm{H}$. who were among the authors of the top 20 most cited papers in this study.

Table 5. Most active authors with minimum 10 papers

\begin{tabular}{|c|c|c|c|c|c|c|c|}
\hline \multirow{2}{*}{ Author } & \multirow{2}{*}{ \# } & \multirow{2}{*}{ Years (Papers) } & \multirow{2}{*}{$\begin{array}{c}\text { Citations } \\
\text { Total }\end{array}$} & $\begin{array}{l}\text { 1st or } 2 n d \\
\text { author(c) }\end{array}$ & \multirow[b]{2}{*}{$\operatorname{Max}(a)$} & \multirow[b]{2}{*}{$\begin{array}{l}\% \text { of } \\
\text { All(b) }\end{array}$} & \\
\hline & & & & Avg. & & & \\
\hline Maurer $\mathrm{F}$. & 29 & $\begin{array}{l}2011(2), 2010(4), 2009(5), 2008(5), \\
2007 \text { (6), } 2006 \text { (2), } 2005 \text { (1), } 2004 \text { (1), } \\
2002 \text { (3) }\end{array}$ & 178 & 6.14 & 27 (2007) & 6.10 & $\begin{array}{c}17 \\
(29)\end{array}$ \\
\hline $\begin{array}{l}\text { Abrahamsson } \\
\text { P. }\end{array}$ & 18 & $\begin{array}{l}2017 \text { (3), } 2016 \text { (2), } 2015 \text { (2) } 2014 \text { (1), } \\
2013 \text { (1), } 2009 \text { (4), } 2008 \text { (2), } 2007 \text { (1), } \\
2005 \text { (1), } 2004 \text { (1) }\end{array}$ & 85 & 4.72 & $21(2015)$ & 2.91 & $8(18)$ \\
\hline Marchesi M. & 17 & $\begin{array}{l}2018(1), 2016(2), 2015 \text { (2), } 2014 \text { (1), } \\
2013(1), 2012 \text { (1), } 2011(2), 2008 \text { (1), } \\
2007 \text { (3) } 2006 \text { (1), } 2004 \text { (1), } 2003 \text { (1) }\end{array}$ & 113 & 6.65 & $29(2004)$ & 3.87 & $5(17)$ \\
\hline Fraser $\mathrm{S}$. & 16 & $\begin{array}{l}2015 \text { (2), } 2010 \text { (1) } 2009 \text { (1), } 2008 \text { (1), } \\
2007 \text { (1), } 2006 \text { (2), } 2005(2), 2004 \text { (2), } \\
2003 \text { (3), } 2002 \text { (1) }\end{array}$ & 26 & 1.63 & $8(2003)$ & 0.89 & $\begin{array}{c}16 \\
(16)\end{array}$ \\
\hline Wang $X$. & 14 & $\begin{array}{l}2017(3), 2016(1), 2015 \text { (2), } 2014(2), \\
2013(1), 2010(1), 2009(2), 2008 \text { (1) } \\
2006 \text { (1) }\end{array}$ & 56 & 4.00 & 21 (2015) & 1.92 & $7(14)$ \\
\hline Noble J. & 13 & $\begin{array}{l}2015 \text { (1), } 2014 \text { (1), } 2013 \text { (1), } 2012 \text { (1), } \\
2011 \text { (2), } 2010 \text { (3), } 2009 \text { (1), } 2008 \text { (1), } \\
2007 \text { (1), } 2004 \text { (1) }\end{array}$ & 105 & 8.08 & $28(2007)$ & 3.60 & $\begin{array}{c}12 \\
(13)\end{array}$ \\
\hline Sharp H. & 13 & $\begin{array}{l}2018 \text { (1), } 2017 \text { (1), } 2015 \text { (1) } 2014 \text { (1), } \\
2012(1), 2011 \text { (1), } 2010 \text { (2), } 2008 \text { (1), } \\
2006 \text { (2), } 2005 \text { (1), } 2004(1)\end{array}$ & 215 & 16.54 & $92(2006)$ & 7.36 & $\begin{array}{c}10 \\
(13)\end{array}$ \\
\hline Concas G. & 12 & $\begin{array}{l}2014 \text { (3), } 2013 \text { (1), } 2012 \text { (1), } 2011 \text { (2), } \\
2008 \text { (1), } 2007 \text { (2), } 2006 \text { (1), } 2005 \text { (1) }\end{array}$ & 69 & 5.75 & $14(2012)$ & 2.36 & $9(12)$ \\
\hline Dingsøyr T. & 12 & $\begin{array}{l}2018 \text { (3), } 2017 \text { (1), } 2016 \text { (1), } 2015 \text { (2), } \\
2013 \text { (1), } 2011 \text { (1), } 2009 \text { (2), } 2008 \text { (1) }\end{array}$ & 71 & 5.92 & $32(2008)$ & 2.43 & $7(12)$ \\
\hline Holcombe M. & 12 & 2008 (1), 2005 (8), 2004 (1), 2003(2) & 19 & 1.58 & $7(2005)$ & 0.65 & $8(12)$ \\
\hline Succi G. & 12 & $\begin{array}{l}2011 \text { (2), } 2009 \text { (3), } 2008 \text { (1), } 2007 \text { (2), } \\
2005(2), 2004 \text { (1), } 2003(1)\end{array}$ & 52 & 4.33 & $18(2008)$ & 1.78 & $4(12)$ \\
\hline Bosch J. & 11 & $\begin{array}{l}2018(1), 2017(3), 2016(1), \\
2015(3), 2014(2), 2012(1)\end{array}$ & 36 & 3.27 & $15(2012)$ & 1.23 & $6(11)$ \\
\hline Hussman D. & 11 & $\begin{array}{l}2008 \text { (1), } 2007 \text { (2), } 2006 \text { (1), } 2005 \text { (2), } \\
2004 \text { (5) }\end{array}$ & 4 & 0.36 & $1(2005)$ & 0.14 & $6(11)$ \\
\hline Martin A. & 11 & $\begin{array}{l}2017 \text { (1), } 2008 \text { (1), } 2007 \text { (1), } 2006 \text { (1), } \\
2005 \text { (3), } 2004 \text { (3), } 2003 \text { (1) }\end{array}$ & 28 & 2.55 & $12(2005)$ & 0.96 & $\begin{array}{c}10 \\
(11)\end{array}$ \\
\hline Moe N.B. & 10 & $\begin{array}{l}2017 \text { (2), } 2016 \text { (1), } 2015 \text { (1), } 2013 \text { (1), } \\
2012(1), 2011 \text { (1), } 2009 \text { (2), } 2008 \text { (1) }\end{array}$ & 71 & 7.1 & $32(2008)$ & 2.43 & $\begin{array}{c}10 \\
(10)\end{array}$ \\
\hline Mugridge $R$. & 10 & 2005 (5), 2004 (3), 2003 (2) & 16 & 1.60 & $5(2003)$ & 0.55 & $8(10)$ \\
\hline
\end{tabular}


$a=$ M aximum number of citations for a single paper $\&$ publication year of that paper

$b=$ Percentage of the total number of citations ( 2920 for all publications)

$c=$ Number of times as first or second author in the publications

\#=Total number of publications

\subsection{Citation Landscape \& M ost Cited Papers of XP Conference}

A high citation count of a scientific work is an indication of an influential work and impact of a given paper $[2,25]$. Our analysis shows that $62 \%(n=488)$ of the XP papers have been cited at least once, leaving about $38 \%$ ( $n=301)$ as uncited papers, see Fig. 3 . This is an indication of high visibility of XP conference papers. When focusing on the first ten years of the XP conference, i.e., the papers prior to 2012 , nearly $65 \%$ of those papers (352/542) have been cited at least once. The findings are in line with prior studies [10,9] in which about $43 \%$ of the papers were uncited (in a study of large body of SE publications). Similarly, about $42 \%$ of the papers of "International Symposium on Empirical Software Engineering and Measurement" [21] were uncited.

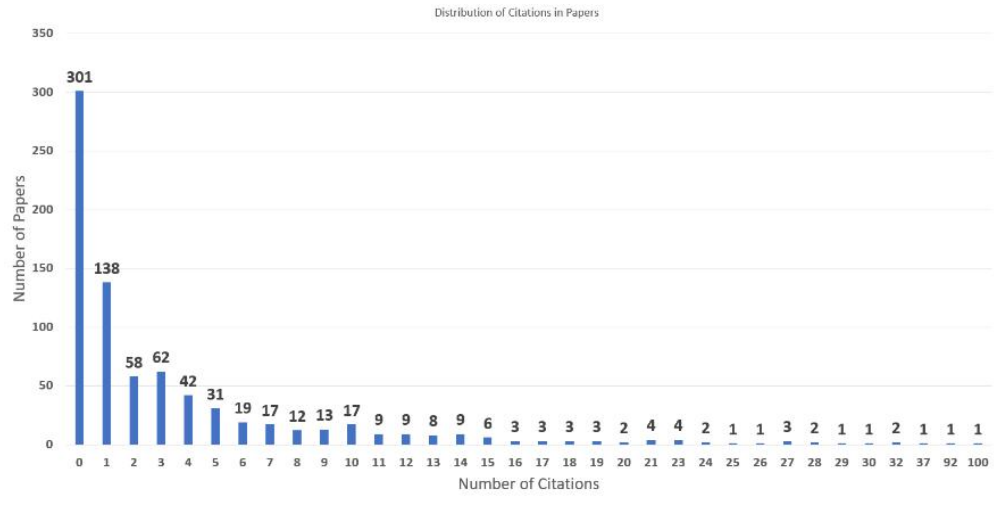

Figure 3. Distribution of citations ( $0-100$ at the time) for the papers

Garfield [6] argues about citation count being the measure of importance or impact of a scientific work. He claims that a citation count is rather a measure of utility, i.e., usefulness of the work for a large number of people or experiments [6]. Furthermore, a citation count can also be a measure of scientific activity and not necessarily related to the significance of the scientific work itself [6]. As in reality, only a rather small portion of the XP conference papers retrieved from Scopus are full research papers, the high number of uncited papers is not a surprise. Thus, it can be claimed that the samples from indexed databases may not be as representative as expected for citation analysis without rigorous filtering. However, such sample papers may well be valid for analysing author activity as well as research trends and topics. The number of citations for all conference papers per year is shown in Fig. 4. The visual information in the bubble graph embeds the timeline (years in the horizontal axis), the number of all conference papers (vertical axis) and the size of the bubble shows the number of citations for the papers published that year. Pearson's correlation coefficient between years passed and the number of citations for the papers of a specific year is 0.76 with $p$-value 0.00041 (which is less than the significance level alpha 0.05). We can conclude that years passed and the number of citations is significantly correlated in this particular conference. Thus, some of the papers from the early years of the conference seem to have been pioneering work and fertile ground for later research. 


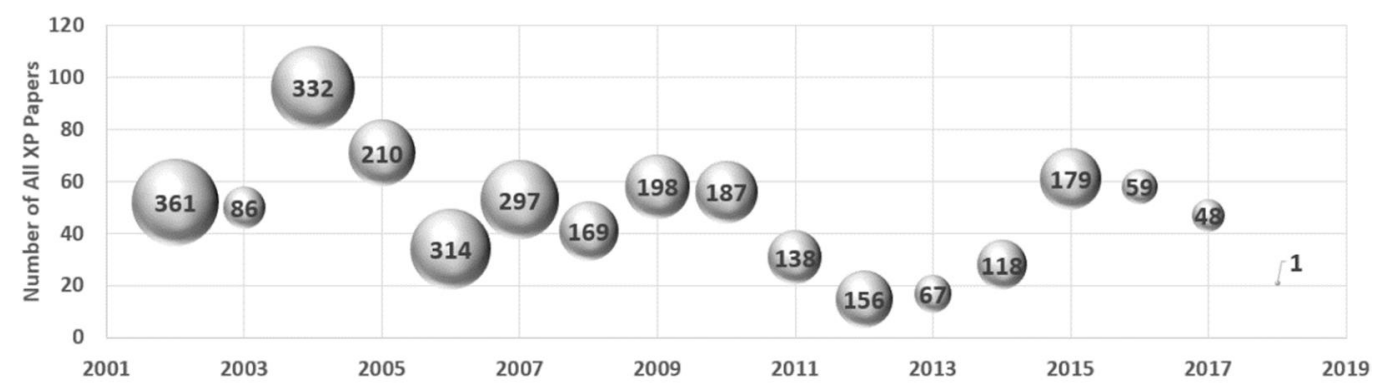

Figure 4. Distribution of citations per year for all papers (2002-2018)

The Table 6 shows the top 20 most cited XP conference papers (each paper having minimum 23 citations). The total number of citations for the top 20 papers covers almost $25 \%$ of all citations (680/2920) which are mainly from earlier years of XP conference (2002-2009). However, one paper is published in 2015 and five papers among the top 20 papers are published in 2002. Table 6 , shows that $92 \%$ of citations $(624 / 680)$ are from papers not written by the authors (of the cited paper) themselves. Such trend indicates high interest towards a study from the research community, although self-citations may sometimes be expected and worthwhile (e.g., when building on previous results of one's own research). Typically, a paper is cited the first time during the year of its publication or during the following year. However, the two top cited papers, "Empirical findings in agile methods" by Lindvall et al. (2002) and "Towards a framework for integrating agile development and user-centred design" by Chamberlain et al. (2006), have been published over ten years ago, and have received the most citations since 2015. Chamberlain et al. (2006) had only a few citations right after its publication. After 2010 until 2015 the paper has received attention from both industry and academics in various fields of science, e.g., Computer Science, M athematics, Decision science, Business, $M$ anagement and Accounting, Social sciences or Psychology. In 2017, Chamberlain et al. (2006) received the most citations among the top 20 cited papers and was the second most cited in 2018 (after Lindvall et al. 2002), at the time of the study.

Table 6. Top 20 cited papers (sorted by the column "All"

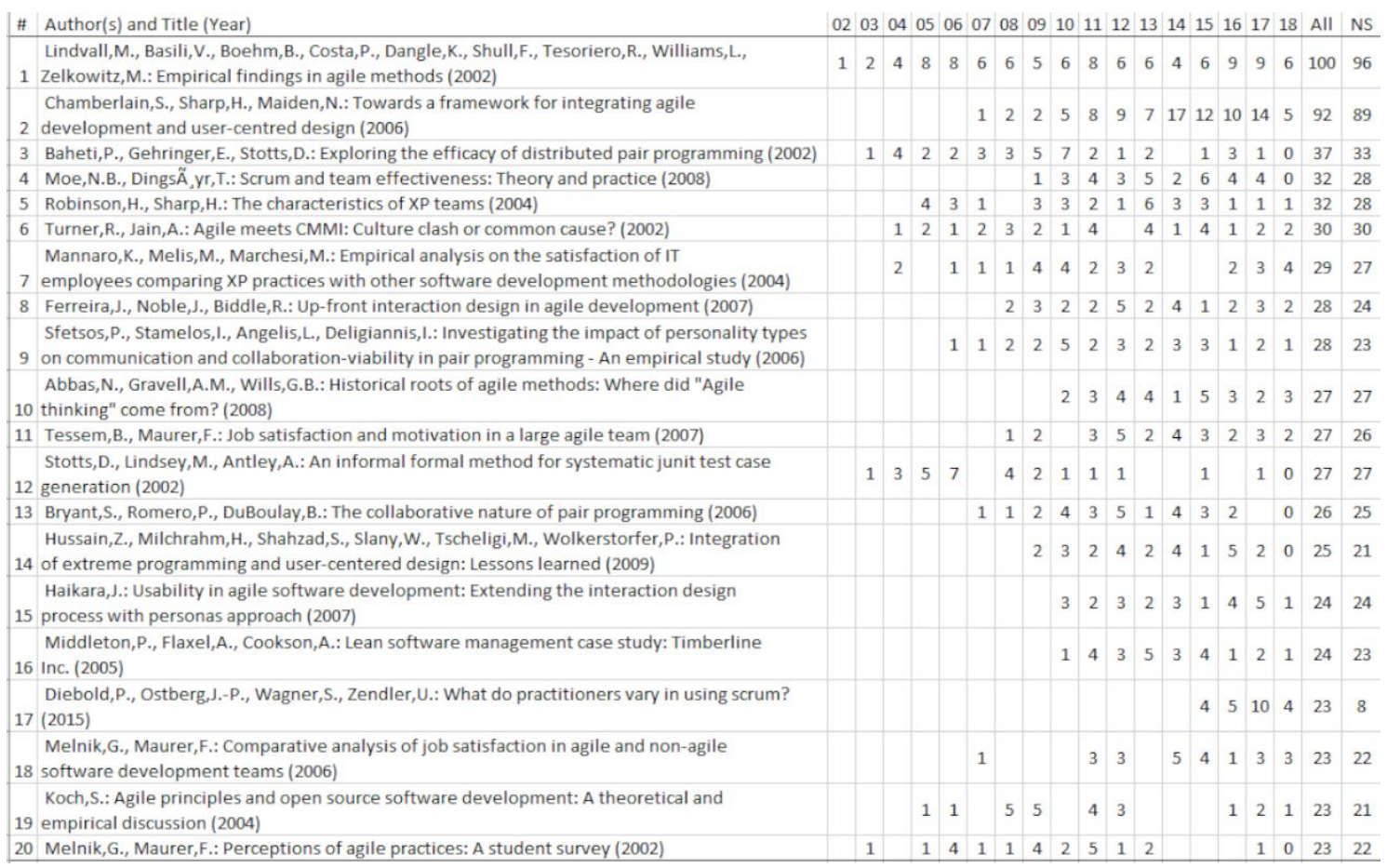




\subsection{Highest Cited Papers Per Year}

Many countries and evaluating bodies (for funding, promotions or appointments) are using figures like publication records or citation counts in decision-making [3]. Such evaluations have two sides; firstly, it is fair to see the influential and trendy work of a specific researcher, and secondly, the appropriateness of such trends or counts can be questioned on scientific grounds. Rapid growth of citations for a paper may be a sign of a popular topic, or active author(s) building on their existing research, or both. Eight of the year-wise most cited papers are the same as reported in Table 6 as the top 20 most cited papers. Those papers have been available for the public for a long period of time, from years 2002 (5), 2004 (3), 2005 (1), 2006 (4), 2007 (3), 2008 (2), 2009 (1) and 2015 (1). The average number of citations for top cited paper per year in Table 7 is 26.6, which is less than the average from top 20 most cited papers, 34 in Table 6.

To compare the general interest on the published papers, we normalized the number of citations for years, see column C-Norm in Table 7. The values for normalized citations varied between 0:53-7:67. The highest number of normalized citations, 7.67, are for the paper "What do practitioners vary in using scrum" by Diebold et al. (2015) which received 23 citations in three years (ranked \#8 in Table 7 considering purely citations). Similarly, the paper "Empirical findings in agile methods" by Lindvall et al. (2002) has been available for twelve years and has 92 citations (similarly, ranked as \#2 in Table 7). The paper also ranked the highest for the number of citations (100, see Table 6) and has the fourth highest normalized citation count (6.25).

Garousi and Fernandes [9] claim that newer papers will first get to be known in the community. According to Raulamo-J urvanen et al [21] the longer the paper has been available the better are the chances to be cited. However, according to our results, recent papers have received more attention in terms of citations. One reason can be that the SE community has grown over the years and recent topical papers may have a slight advantage when it comes to the number of citations per year.

We were curious to see whether the length of the title had impact on the number of citations for a paper. In the findings of Letchford et al. [17], the relationship between the lengths of paper titles and citations (across various journals) concluded a short title for a paper to be an advantage for receiving citations. However, they also noted that the evidence is not as strong when it is adjusted for the journal where the paper is published. For the XP papers, the correlation between the length of the title, either in words or in characters, and the number of citations is weak ( $r=0: 03 ; d f=787 ; p=0: 415$ and $r=0: 04 ; d f=787 ; p=0: 235$, respectively). The top 5 cited papers have rather short titles (length varying from 31 to 77 in characters and from 5 to 10 in words). The median length of all titles, in characters and words is 62 and 8 , respectively.

\subsection{Topical Issues}

With topic modeling, we analyzed the abstract topics in the combined text of abstracts and titles of the papers. Topic modeling is a statistical way to analyze contents of a collection of papers. First, we removed 66 papers from the original pool of 789 papers, as the data retrieved from Scopus did not include abstracts for those 66 papers. Thus, the set of papers for trend analysis included 723 papers. To have an overview of the topics covered in the papers, we combined the titles and the abstracts of the papers, converted the text to lowercase and removed all (English) stopwords from the text in R. (A stopword is a commonly used word, a useless word like "the"). For the trend analysis we utilized topic modeling and Latent Dirichlet Allocation (LDA) as described by Grffiths and Steyvers [13] with R scripts based on an approach of Ponweiser [20]. LDA is an algorithm used for classifying the text in a paper to some topics (mixture of topics) and each topic to a mixture of terms (words). Our approach was identical to the process used by Raulamo-Jurvanen et al. [21] and Garousi and Mäntylä [10]. We created a document term matrix from the corpus (using R "text2vec" 
Table 7. Top cited papers per year (2002-2018)

\begin{tabular}{|c|c|c|c|}
\hline Author(s) and Title & Cites & C-Norm (a) & \#(b) \\
\hline $\begin{array}{l}\text { Lindvall,M., Basili,V., Boehm,B., Costa,P., Dangle,K., Shull,F., Tesoriero,R., Williams,L., Zelkowitz,M.: } \\
\text { Empirical findings in agile methods }\end{array}$ & 100 & 6.25 & 4 \\
\hline Lowell C.,Stell-Smith J.:Successful automation of GUI driven acceptance testing & 8 & 0.53 & 17 \\
\hline RobinsonH.,SharpH.: The characteristics of XP teams & 32 & 2.29 & 12 \\
\hline Middleton,P., Flaxel,A., Cookson,A.: Lean software management case study: Timberline Inc. & 24 & 1.85 & 14 \\
\hline $\begin{array}{l}\text { Chamberlain,S., Sharp,H., Maiden,N.: Towards a framework for integrating agile development and user- } \\
\text { centred design }\end{array}$ & 92 & 7.67 & 1 \\
\hline Ferreira,J., Noble,J., Biddle,R.: Up-front interaction design in agile development & 28 & 2.55 & 10 \\
\hline M oeN.B.,DingsøyrT.: Scrum and team effectiveness: Theory and practice & 32 & 3.20 & 7 \\
\hline $\begin{array}{l}\text { Hussain,Z., Milchrahm,H., Shahzad,S., Slany,W., Tscheligi,M., Wolkerstorfer,P.: Integration of extreme } \\
\text { programming and user-centered design: Lessons learned }\end{array}$ & 25 & 2.78 & 9 \\
\hline $\begin{array}{l}\text { FerreiraJ .,SharpH.,RobinsonH.: Values and assumptions shaping Agile development and User } \\
\text { Experience design in practice }\end{array}$ & 14 & 1.75 & 15 \\
\hline DorairajS.,NobleJ.,MalikP.: Effective communication in distributed agile software development teams & 15 & 2.14 & 13 \\
\hline $\begin{array}{l}\text { StaronM.,M edingW.,PalmK.: Release readiness indicator for mature agile and lean software } \\
\text { development projects }\end{array}$ & 21 & 3.50 & 5 \\
\hline $\begin{array}{l}\text { HeikkiläV.T.,PaasivaaraM .,LasseniusC.,EngblomC.: Continuous release planning in a large-scale scrum } \\
\text { development organization at ericsson }\end{array}$ & 12 & 2.40 & 11 \\
\hline LiskinO.,PhamR.,KieslingS.,SchneiderK.: Why we need a granularity concept for user stories & 12 & 3.00 & 8 \\
\hline Diebold,P.,Ostberg,J.-P.,Wagner,S.,Zendler,U.: What do practitioners vary in using scrum? & 23 & 7.67 & 1 \\
\hline $\begin{array}{l}\text { OrtuM .,DestefanisG.,CounsellS.,SwiftS.,TonelliR.,MarchesiM .: Arsonists or firefighters? Effectiveness in } \\
\text { agile software development }\end{array}$ & 7 & 3.50 & 5 \\
\hline $\begin{array}{l}\text { TaibiD.,LenarduzziV.,J anesA.,LiukkunenK.,AhmadM .O.: Comparing requirements decomposition within } \\
\text { the Scrum, Scrum with Kanban, XP, and Banana development processes }\end{array}$ & 7 & 7.00 & 3 \\
\hline $\begin{array}{l}\text { OyetoyanT.D.,M ilosheskaB.,GriniM .,SoaresCruzesD.: Myths and facts about static application security } \\
\text { testing tools: An action research at telenor digital }\end{array}$ & 1 & 1.00 & 16 \\
\hline
\end{tabular}

package, https://cran.r-project.org/web/packages/text2vec/index.html), excluding words having less than two characters or appearing in less than three papers. We generated a LDA model (using R "topicmodels" package, https://cran.r-project.org/web/packages/topicmodels/index.html) by running the topic models from 2 to 100 by one, yielding 35 as the optimal number of topics. 
In the analysis of the trend slopes (by publication year) the topics gaining interest among the authors are the "hot topics" and the topics declining interest are the "cold topics". The five hottest and coldest topics, interpreted by the topic-specific words (and related titles), and 10 significant terms for each of those, are shown in Table 8a and Table 8b, respectively. The topics gaining the most interest are "Coordination" and "Technical Debt", which include issues like largescale coordination and interteam objectives as well as metrics and automation. Cold topics such as "Education", "Methods and Practices" (including pair programming) and "Testing", have been of less inspiration for the submissions during the recent years of the XP conference.

In 2012, the key research themes in agile software development at the time, reported by Dingøsyr et al. [4], were Case Study M ethodology, Traditional Software Engineering, CM M, Project Management, Software estimation, Pair Development, Distributed Cognition, Agile methods, User-centered design, Agile methodologies and Patterns. Some of those themes seem still topical, e.g., software estimation as "Technical Debt" and some not, like Pair Development or Agile Methods as "M ethods and Practices" (see Table 9a and Table 9b). In that study, the research topics worth further research were collected from academics attending the Agile2011 conference [4]. Pair programming in educational settings and reuse of code were considered as fading topics while topics like agile across projects and across organizations and distributed agile development were considered as important topics, requiring further research. "We concur that these are exciting research areas that can further our understanding of the effectiveness of agile methods and practices, particularly in different project/organizational contexts" [4]. Such trend was also visible in our prior study, as "Education" and "M ethods and Practices" (including pair programming) were found to be cold topics and topics like "Coordination" and "Teamwork" were among the hot topics [21]. Questions related to topics of interest, for both academics and practitioners in the field, should be asked from those stakeholders on a regular basis, to support the needs or interests in the industry, too.

\subsection{Indexed Keywords}

To study the published topics from another perspective, we collected the indexed keywords from Scopus. It is notable that we used the indexed keywords (not the author keywords), as in the data set the indexed keywords outnumbered the author keywords, providing more details. Additionally, there are papers that are not only missing abstracts (see Chapter 3.4) but also keywords (see Scopus e.g., a conference paper "Agile acceptance testing" by Pettichord and Marick from 2002). There were 720 papers with indexed keywords. The minimum number of indexed keywords for a paper was 3, the maximum was as high as 25 (for one paper) and arithmetic mean 9.4. We checked the correlation between the number of indexed keywords and the number of citations for a paper, but that correlation is weak ( $r=0: 028 ; d f=718 ; p=0: 459$ ).

We paired the keywords for each paper (e.g., a paper having four keywords would eventually yield 6 unique keyword pairs). Any spaces in between words of a single keyword were removed (to generate a single combined word) and those keywords were then converted to lower case and capitalized. The pairing resulted in 32131 keyword pairs which we then stored in a csv-file. We used Cytoscape for visualizing the network of the paired keywords (after removing duplicates), see Fig. 5. The lighter the background color of a keyword, the more the keyword had connections (pairs). The keyword "software engineering" was, unsurprisingly, the most used keyword, see Fig. 5. The nine other most used keywords were "software design", "agile software development", "agile methods", "computer programming", "project management" , "computer software", "agile development", "extreme programming", "agile" and "software testing". The keywords are rather generic, but still quite nicely represent the key research themes identified by Dingsøyr et al. [4]. However, a more detailed analysis of the keywords, to view the overall importance and reveal the topicality of the keywords, would be required to see the trends in the area of XP. 
Table 8. Hot and cold topics and number of papers for each topic

Table 8a. Hot topics

\begin{tabular}{|c|c|c|c|c|}
\hline Coordination & Technical Debt & Teamwork & Startups & Agile Practices \\
\hline 24 & 21 & 23 & 18 & 30 \\
\hline $\begin{array}{l}\text { largescale } \\
\text { coordinate } \\
\text { mechanism } \\
\text { tailor } \\
\text { interteam } \\
\text { userstory } \\
\text { standard } \\
\text { story } \\
\text { objectives } \\
\text { human }\end{array}$ & $\begin{array}{l}\text { technical } \\
\text { debt } \\
\text { metric } \\
\text { evolution } \\
\text { td } \\
\text { production } \\
\text { automatic } \\
\text { stakeholders } \\
\text { monitored } \\
\text { influencing }\end{array}$ & $\begin{array}{l}\text { meeting } \\
\text { retrospective } \\
\text { reflection } \\
\text { standup } \\
\text { commitment } \\
\text { workshop } \\
\text { education } \\
\text { scalability } \\
\text { guideline } \\
\text { enhance }\end{array}$ & $\begin{array}{l}\text { startup } \\
\text { devops } \\
\text { prototype } \\
\text { stage } \\
\text { speed } \\
\text { sprints } \\
\text { monitoring } \\
\text { pressure } \\
\text { theoretical } \\
\text { attempts }\end{array}$ & $\begin{array}{l}\text { scrum } \\
\text { kanban } \\
\text { board } \\
\text { barriers } \\
\text { wip } \\
\text { selforganizing } \\
\text { multitasking } \\
\text { automotive } \\
\text { optimization } \\
\text { transformations }\end{array}$ \\
\hline \multicolumn{5}{|c|}{ Table 8b. Cold topics } \\
\hline Process Simulation & Education & $\begin{array}{l}\text { Coaching \& } \\
\text { Experimenting }\end{array}$ & Testing & $\begin{array}{l}\text { M ethods and } \\
\text { Practices }\end{array}$ \\
\hline 52 & 28 & 17 & 21 & 31 \\
\hline $\begin{array}{l}\mathrm{xp} \\
\text { simulation } \\
\text { integrate } \\
\text { budget } \\
\text { units } \\
\text { leadership } \\
\text { waterfall } \\
\text { events } \\
\text { tester } \\
\text { userinterface }\end{array}$ & $\begin{array}{l}\text { student } \\
\text { teach } \\
\text { university } \\
\text { education } \\
\text { curriculum } \\
\text { skill } \\
\text { classroom } \\
\text { testable } \\
\text { selforganizing } \\
\text { comprehensive }\end{array}$ & $\begin{array}{l}\text { coach } \\
\text { languages } \\
\text { transition } \\
\text { mock } \\
\text { panel } \\
\text { standard } \\
\text { tutorial } \\
\text { certified } \\
\text { exercises } \\
\text { shares }\end{array}$ & $\begin{array}{l}\text { acceptance } \\
\text { executable } \\
\text { version } \\
\text { regulations } \\
\text { workshop } \\
\text { testdriven } \\
\text { packages } \\
\text { technical } \\
\text { classify } \\
\text { methodological }\end{array}$ & $\begin{array}{l}\text { pair } \\
\text { programmer } \\
\text { experiment } \\
\text { skill } \\
\text { tester } \\
\text { switching } \\
\text { assist } \\
\text { standard } \\
\text { structures } \\
\text { expectations }\end{array}$ \\
\hline
\end{tabular}

\subsection{Author Collaboration}

Table 5 presents the most active authors and Table 4 the proportion of the number of authors yearly. We were also interested in analyzing the "clusters of collaboration" among the authors of the XP. The collaboration between the authors is measured with the total number of different co-authors in their papers (within the scope of the XP papers). For analyzing the collaboration, we changed the author names to lower case letters and combined the first initial(s) to make a difference between two authors with the same last name (e.g., Poppendieck M . is "poppendieckm" and Poppendieck T. is "poppendieckt"). Then, we paired the author names for the papers (just as we paired the keywords for each paper, as explained in Section 3.5). From observing the collaboration, we could conclude that roughly half of the authors (about $47 \%$ ) have written their papers either by themselves or with just one collaborator. There are a few "clusters of authors", indicating that there are groups of researchers and/or practitioners that work together on the topic of XP. It would be interesting to study whether those different "clusters of collaboration" have e.g., focused on different topics, used different research methods or cited each other's papers in their research. (Of course, it is notable that not all papers in XP are "full papers"). 


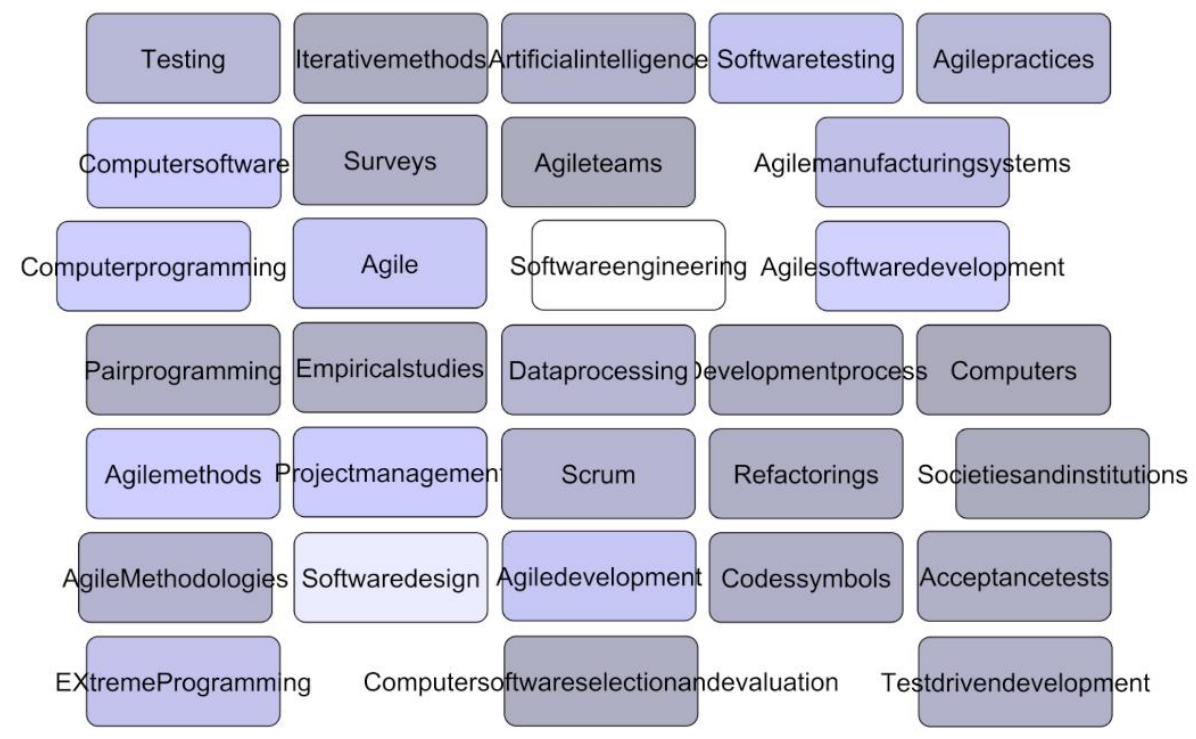

Figure 5. Visualization of the most used indexed keywords (31)

The 15 "top collaborating authors" (i.e., those having the most co-published papers) have been contributing to the forum from early on and they have from 17 to 54 collaborators within the forum, see Table 9. Many of those authors have not only collaborated with different researchers and/or practitioners but have also been active publishing in the forum, see the column "Rank in Table 5" in Table 9. It seems the top collaborating authors have many connections, but the collaboration network among those top authors themselves has not been very active, see Table 10. There are two authors among the top collaborators that have not collaborated with any of the other top collaborators, namely Sharp H. and Dingsøyr T. On the other hand, there are three top collaborators that have collaborated with several other top collaborators: Fraser S. (9), Martin A. (7) and Eckstein J. (7). Collaboration, or lack of it among the top collaborators (and among all authors) could be due to various reasons, e.g., different affiliations or differing research interests (e.g., specific research topic-wise or research method-wise).

We selected the top three authors having the most collaboration (i.e., the most co-authors, see Table 9) and the co-authors in their XP papers. Those authors form a "cluster of collaboration", a network of 117 authors. To get an overview of their collaboration, we used Cytoscape for visualizing the network of the paired authors (after removing duplicates) for the top three authors of the Table 9: frasers, abrahamssonp and maurerf, see Fig. 6, Fig. 7 and Fig. 8, respectively. The lighter the background color of the author name, the more it has connections. From the figures we can observe that Fraser $\mathrm{S}$. is collaborating a lot with authors that are very collaborative themselves, too, while e.g., the co-authors for M aurer F. have less connections among the other authors of the XP papers. A high number of collaboration among authors is not only a sign of interest in publishing but also implies high level of expertise in the topic. However, when looking at the big picture, there are clear "clusters of collaboration" among the authors implying those authors may focus on slightly different topics within the field of agile software development. From studying author collaboration, other researchers, students or those researchers themselves may also find new names for collaboration or followup.

We decided not to analyze the collaboration between the different affiliations for three main reasons. M ost importantly, the information about affiliations was not available (in the raw data from Scopus) for all papers. Secondly, the names of the affiliations may be lengthy and thus di cult to differentiate without information about the location. Thirdly, it is the researchers doing the work and our intention is not to study e.g., funding related issues. For example, a person interested in finding authors writing about specific topics, could do a 
Table 9. Top collaborators in the papers (2002-2018)

\begin{tabular}{|c|c|c|c|c|c|c|}
\hline Author & $\#(\mathrm{a})$ & $\begin{array}{l}\text { Since } \\
\text { (b) }\end{array}$ & $\begin{array}{l}\text { All papers } \\
\text { (c) }\end{array}$ & $\begin{array}{l}\text { Rank in } \\
\text { Table } 5 \\
\text { (d) }\end{array}$ & $\begin{array}{l}\text { \# of } \\
\text { Papers } \\
\text { in Table } 6 \\
\text { (e) }\end{array}$ & $\begin{array}{l}\text { \# of Papers } \\
\text { in Table } 7 \text { (f) }\end{array}$ \\
\hline Fraser S. & 54 & 2002 & 16 & 4 & --- & --- \\
\hline Abrahamsson P. & 36 & 2004 & 18 & 2 & -- & --- \\
\hline M aurer $\mathrm{F}$. & 36 & 2002 & 29 & 1 & 3 & --- \\
\hline M archesi M . & 29 & 2003 & 17 & 3 & 1 & 2016 \\
\hline Wang X. & 28 & 2006 & 14 & 5 & --- & --- \\
\hline Concas G. & 28 & 2005 & 12 & 8 & --- & --- \\
\hline$M \operatorname{artin} A$. & 23 & 2003 & 11 & 14 & --- & --- \\
\hline Eckstein J. & 21 & 2002 & 8 & --- & -- & --- \\
\hline Hussman D. & 20 & 2004 & 11 & 13 & --- & --- \\
\hline Succi G. & 20 & 2003 & 12 & 11 & --- & --- \\
\hline Poppendieck M. & 19 & 2003 & 9 & --- & --- & -- \\
\hline Sharp H. & 19 & 2004 & 13 & 7 & 2 & $\begin{array}{l}2004,2006 \text {, } \\
2010\end{array}$ \\
\hline Dingsøyr T. & 18 & 2008 & 12 & 9 & 1 & 2008 \\
\hline Holcombe M. & 18 & 2003 & 12 & 10 & --- & --- \\
\hline Wild W. & 17 & 2004 & 6 & --- & --- & --- \\
\hline
\end{tabular}

[a] \#=Number of Collaborators in the forum

[b] Published in the forum since the given year

[c] Number of papers published by the author in the XP conference (2002-2018)

[d] Rank in Table5, active authors

[e] Number of papers in Table 6, most cited

[f] Number of papers in Table 7, most cited per year

Table 10. Collaboration of top collaborators in the papers (2002-2018)

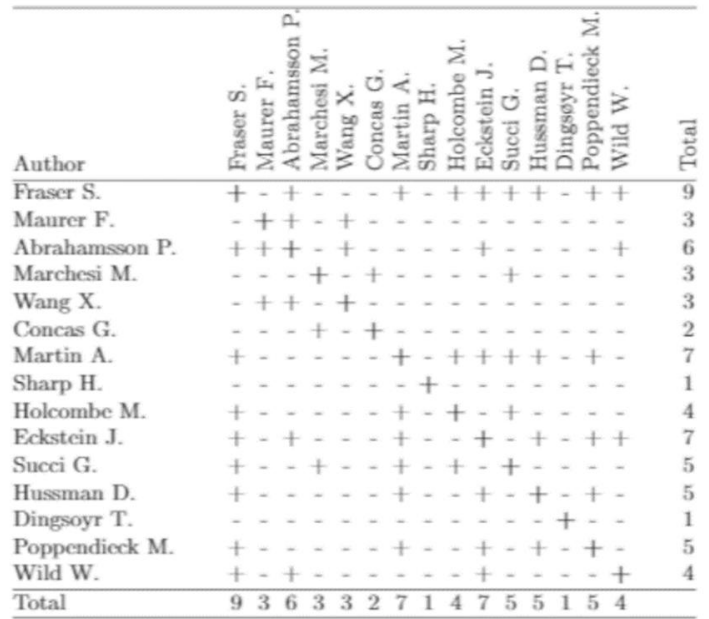


topic analysis or find papers with specific keywords from a database, and then analyze the related authors and their collaboration. We studied the collaboration of the authors among the topics presented in Section 3.4 and list the ten authors having the most collaboration within those topics combined, see Table 11. Academic research is not just about citations but about finding interesting results that can be shared with stakeholders, either with researchers or with practitioners in the industry, or with both. It is interesting to see that researchers working on more fresh, "emerging topics" are collaborating actively, too.

\begin{tabular}{|c|c|c|c|c|c|c|}
\hline pierced & aroi & newkirkj & meer & bornsteing & mattsc & beckk \\
\hline holcombem & caputob & ecksteinj & francisac & jarvinenj & kruchtenp & martina \\
\hline powerk & risingl & adamsm & mackinnont & reinitzr & poppendieckm & mancld \\
\hline wirfsbrockr & poolec & hillm & auerk & amblers & vilkkik & kiviojah \\
\hline chilleyc & jarkvikj & daviesr & pages & striebeckm & mugridger & cunninghamw \\
\hline abrahamssonp & succig & rainsbergerjb & biddler & lundhe & andersond & kerievskyj \\
\hline swana & risinl & wildw & alterhaugb & cusumanom & frasers & larsend \\
\hline hussmand & dubinskyy & agerfalkpj & korsont & boehmb & poppendieckt & \\
\hline
\end{tabular}

Figure 6. Authors collaborating with Fraser S. (54)

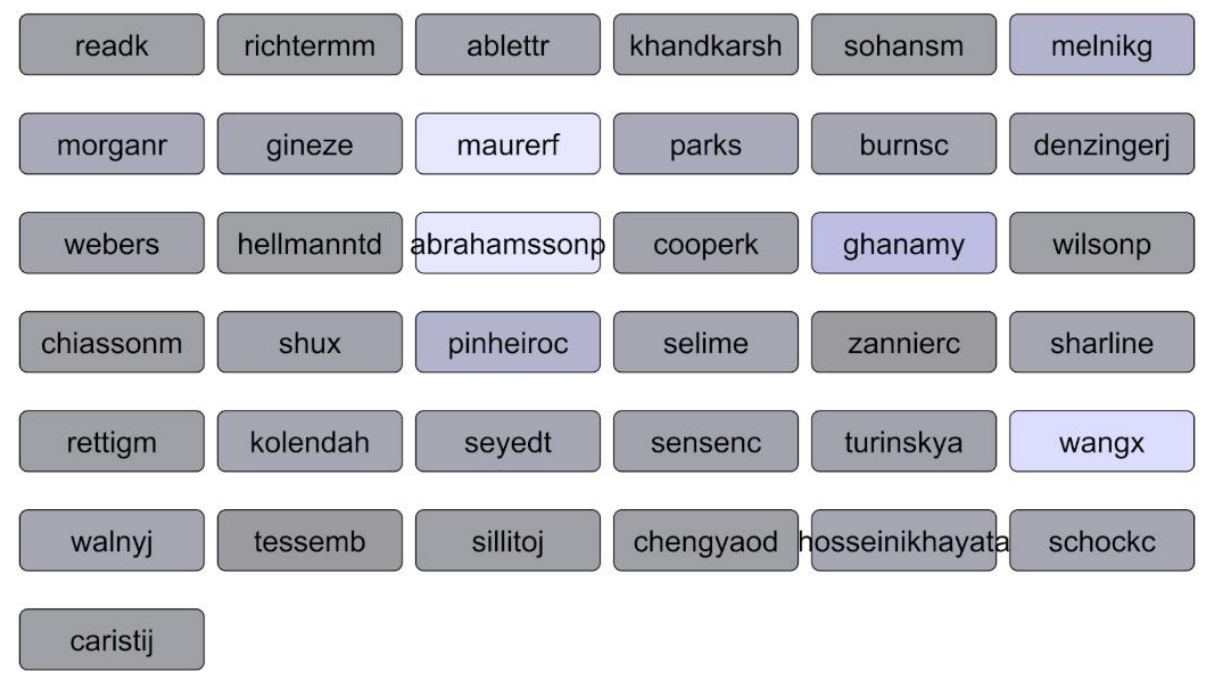

Figure 7. Authors collaborating with Abrahamsson P. (36) 


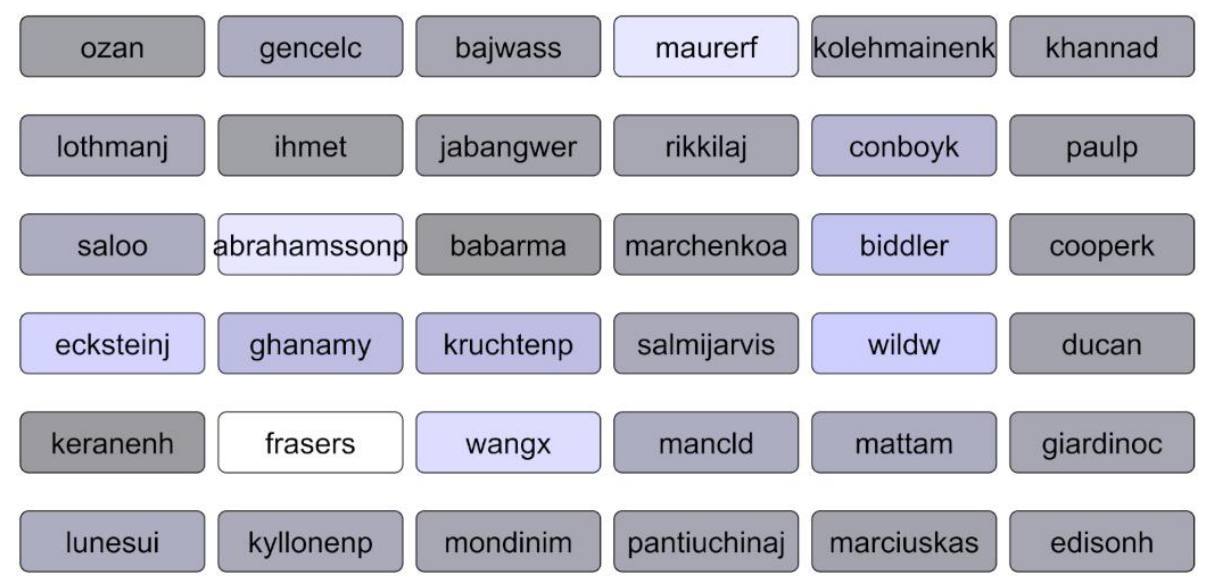

nguyenduca

Figure 8. Authors collaborating with Maurer F. (36)

Table 11. Top collaborators in the papers covering topic presented in Section 3.4

\begin{tabular}{|l|c|}
\hline Author & $\begin{array}{c}\text { Within } \\
\text { Hot Topcis }\end{array}$ \\
\hline Marchesi M. & 17 \\
\hline Wang X. & 17 \\
\hline Concas G. & 14 \\
\hline Taibi D. & 10 \\
\hline Abrahamsson & \\
P. & 9 \\
\hline Kuvaja P. & 9 \\
\hline Rodriguez P. & 9 \\
\hline Dingsoyr T. & 8 \\
\hline Ahmad M.O. & 8 \\
\hline Bosch J. & 8 \\
\hline Martini A. & 8 \\
\hline
\end{tabular}

\begin{tabular}{|l|c|}
\hline Author & $\begin{array}{c}\text { Within } \\
\text { Cold Topcis }\end{array}$ \\
\hline Fraser S. & 20 \\
\hline $\begin{array}{l}\text { Holcombe } \\
\text { M. }\end{array}$ & 13 \\
\hline Crispin L. & 11 \\
\hline Gregory J. & 11 \\
\hline & 11 \\
Lundh E. & 10 \\
\hline Rising L. & 9 \\
\hline Beck K. & 9 \\
\hline Maurer F. & 9 \\
\hline Williams L. & \\
\hline
\end{tabular}

\section{Threats to Validity}

Every research study is prone to a variety of validity threats. We used the guide-lines presented by Wohlin [25] to analyse the threats to validity. Internal validity reflects the extent to which a causal conclusion based on a study is warranted [25]. In our study, the data collection and analysis is presented comprehensively in Section 2 along with a link to access the raw data (https:// bit.ly/2LiqQ3S) and used scripts. In this way, we were aiming to ensure repeatability and reproducibility of our study.

Construct validity is concerned with issues to what extent the object of study truly represents the theory behind the study [25]. Scopus claims to be to be "the largest abstract and citation database of peer-reviewed literature" (https:// www.elsevier.com/solutions/scopus). Our data set is extracted from the Scopus database and we rely on that data as it is provided to all users of that service. However, we noticed that that the papers 
of year 2011 were not properly indexed and that forced us to fetch those missing papers manually (see Table 1). We present the previous finding as a limitation and explain that data retrieved from a database like Scopus may not be $100 \%$ accurate considering e.g., citation counts or author names. Regarding the citations counts, we used only the figures available from Scopus. The author names may be problematic in a bibliometrics analysis like this, as names may be spelled in a different way in different papers and special characters may need to be processed for analysis tools (for example, a Finnish name "Päivi" can be written in English as "Paivi", or there may be cases where the name of an author may cause confusion, e.g., in the case of "NguyenDuc A." or "Duc A.N."). Such problems may be extremely difficult to observe in cases where the data set is very large.

Conclusion validity of a study deals with whether correct conclusions are reached through rigorous and repeatable treatments [25]. The results of this study were elaborated with quantitative measures and statistics based on the extracted data. Based on such approach, any replications of this study will not have major deviations from our results. External validity is concerned with the extent the results of this secondary study for generalization [25]. This study was based on the analysis of the XP conference publications and cannot be generalized to the whole software engineering field. However, our approach was to identify the top cited papers, the emerging hot topics, the citation landscape and the most active and collaborative authors of the XP conference papers in SE area.

\section{Conclusions and Future Work}

This paper identifies and classifies: the highly cited papers, topic trends, topindividuals, authors collaboration and institutes who have significantly published in the XP conference since 2002 until 2018. The trend of the papers shows that the XP conference has received interest from both the academic community and industry. The papers highlight that much of research is stirred by practices emerging in industry. Overall, $62 \%$ of the XP conference papers received at least one citation, which is a sign of good visibility relevance of the published papers. However, about $38 \%$ of the XP papers so far have received no citations at all. This raises questions such as: what are the reason(s) of non-cited XP conference papers? Does this have anything to do with paper or venues' quality? Or, is it about the topics of the papers, the indexed keywords, or the keywords provided by the author(s)? The data, which we make publicly available, can be used to conduct various analysis (i.e., characteristics of highly cited papers) on XP conference papers.

The analysis shows that XP community interest has been moving away from "Process Simulation", "Education" and "Coaching \& Experimenting" related topics to more practice and process-oriented topics. According to the trend analysis, the hottest research topics, i.e., the topics gaining the most interest are "Coordination", "Technical Debt", "Teamwork", "Startups" and"Agile Prac-tices". The identified trends are helpful for both researchers and practitioners to see topics that have more impact and to align their future research activities.

The study found an active core intellectual pool of authors along with their highly cited work. The newbie researchers can start their journey from these papers and follow listed active researchers to stay up to date about latest trends in the Agile world. Additionally, the active publishing institutes in the XP conference can be helpful for doctoral students to approach experts on the specific topic for further research and doctoral studies. We hope that this paper encourages further discussions in the SE community towards further analysis and formal characterization of the highly cited software engineering papers in general and specifically in XP conference community. The important thing about citation count is that it is an "objective measure of the utility or impact of the scientific work" [6]. 
Our future work directions include replication of this analysis for other SE publication venues in order to conduct comparison between research venues and provide more depth to our analysis. In addition, we intend to mine typical features for highly cited papers and to assess the extent to which the inner quality, external features and the reputation of both the authors and journals of the pa-pers contribute to generation of highly cited papers in the future. Furthermore, we consider studying the indexed keywords within a publication venue, in more detail, e.g., by years, to see whether we could find trends from those, too.

\section{References}

1. Ahmad, O.M., Raulamo-Jurvanen, P.: Preliminary citation and to pic analysis of international conference on agile software development papers (2002-2018). In: Fed-CSIS 2019 (Sep 2019)

2. Aksnes, D.W.: Characteristics of highly cited papers. Research Evaluation 12(3), 159-170 (12 2003), doi: $10.3152 / 147154403781776645$

3. Chuang, S.W., Luor, T., Lu, H.P.: Assessment of institutions, scholars, and contributions on agile software development (2001-2012). Journal of Systems and Software 93, 84-101 (2014), doi: 10.1016/j.jss.2014.03.006

4. Dings yr, T., Nerur, S., Balijepally, V., M oe, N.B.: A decade of agile methodologies: Towards explaining agile software development. J ournal of Systems and Software. Special Issue: Agile Development. 85(6), 1213-1221 (2012), doi: 10.1016/j.jss.2012.02.033

5. Farhoodi, R., Garousi, V., Pfahl, D., Sillito, J.: Development of scientific software: a systematic mapping, bibliometrics study and a paper repository. Int. J. Softw. Eng. Knowl. Eng. 23(4), 463-506 (2013), doi: $10.1142 /$ S0218194013500137

6. Garfield, E.: Is citation analysis a legitimate evaluation tool? Scientometrics 1(4), 359-375 (May 1979), doi: 10.1007/BF02019306

7. Garfield, E.: Citation indexes for science. A new dimension in documentation through association of ideast. International Journal of Epidemiology 35(5), 1123-1127 (09 2006), doi: 10.1093/ije/dyl189

8. Garousi, V., Fernandes, J.M.: Highly-cited papers in software engineering: The top-100. Information and Software Technology 71, 108-128 (2016), doi: 10.1016/j.infsof.2015.11.003

9. Garousi, V., Fernandes, J.M.: Quantity versus impact of software engineering papers: a quantitative study. Scientometrics 112(2), 963-1006 (Aug 2017), doi: 10.1007/s11192-017-2419-6

10. Garousi, V., Mäntylä, M.V.: Citations, research topics and active countries in software engineering: A bibliometrics study. Computer Science Review 19, 56-77 (2016), doi: 10.1016/j.cosrev.2015.12.002

11. Garousi, V., Varma, T.: A bibliometric assessment of canadian software engineering scholars and institutions (1996-2006). Computer and Information Science 2(2), 19-29 (2010)

12. Glass, R.L., Vessey, I., , Ramesh, V.: Research in software engineering: an analysis of the literature. Information and Software Technology 44(8), 491-506 (2002), doi: 10.1016/S0950-5849(02)00049-6

13. Griffiths, T.L., Steyvers, M.: Finding scientific topics. Proceedings of the National Academy of Sciences 101(suppl 1), 5228-5235 (2004), doi: 10.1073/pnas.0307752101

14. Hoonlor, A., Szymanski, B.K., Zaki, M.J.: Trends in computer science research. Commun. ACM 56(10), 7483 (Oct 2013), doi: 10.1145/2500892 
15. Karanatsiou, D., Li, Y., Arvanitou, E.M., M isirlis, N., Wong, W.E.: A bibliometric assessment of software engineering scholars and institutions (2010-2017). Journal of Systems and Software 147, 246-261 (2019), doi: 10.1016/j.jss.2018.10.029

16. Kitchenham, B.: What's up with software metrics? - a preliminary mapping study. Journal of Systems and Software 83(1), 37-51 (2010), doi: 10.1016/j.jss.2009.06.041

17. Letchford, A., M oat, H.S., Preis, T.: The advantage of short paper titles. Royal Society Open Science 2(8), 1-6 (2015), doi: 10.1098/rsos.150266

18. Noorden, R.V., Maher, B., Nuzzo, R.: The top 100 papers. Nature 514(7524), 550-553 (2014), doi: $10.1038 / 514550 a$

19. OECD: Oecd frascati manual, sixth edition, annex 7, paras. 20-22, oxford dictionaries, 2013, website (2013), https://stats.oecd.org/glossary/ detail.asp?ID=198, accessed on Sep 4th 2019.

20. Ponweiser, M.: Latent Dirichlet Allocation in R. M aster's thesis, Institute for Statistics and Mathematics, University of Economics and Business, Vienna, Austria (2012)

21. Raulamo-Jurvanen, P., M äntylä, M .V., Garousi, V.: Citation and topic analysis of the esem papers. In: 2015 ACM /IEEE International Symposium on Empirical Software Engineering and Measurement (ESEM ). pp. 1-4 (Oct 2015), doi: 10.1109/ESEM .2015.7321193

22. Wohlin, C.: An analysis of the most cited articles in software engineering journals.1999. Information and Software Technology 47(15), 957-964 (2005), doi: 10.1016/j.infsof.2005.09.002

23. Wohlin, C.: An analysis of the most cited articles in software engineering journals - 2000. Information and Software Technology 49(1), 2-11 (2007), doi: 10.1016/j.infsof.2006.08.004

24. Wohlin, C.: An analysis of the most cited articles in software engineering journals - 2001. Information and Software Technology 50(1), 3-9 (2008), doi: 10.1016/j.infsof.2007.10.002

25. W ohlin, C., Runeson, P., H ost, M., Ohlsson, M.C., Regnell, B., Wessl] en, A.: Experimentation in Software Engineering: An Introduction, International Series in Software Engineering, vol. 6. Springer US (2000), doi: 10.1007/978-1-4615-4625-2 